\title{
Does the Breast Size in Females Correlate with the Severity of Mechanical Low Back Pain?
}

\author{
Emmanuel C. Iyidobi ${ }^{1}$, Osita Ede ${ }^{1}$, Chinenye C. Obi ${ }^{1}$, Violet O. Onwuekwe ${ }^{1}$, \\ Cajethan U. Nwadinigwe ${ }^{1}$, Theclar 0. Iyidobi2*, Oke R. Obadaseraya ${ }^{1}$ \\ ${ }^{1}$ Department of Orthopaedics and Trauma, National Orthopaedic Hospital, Enugu, Nigeria \\ ${ }^{2}$ Department of Psychological Medicine, University of Nigeria Teaching Hospital, Enugu, Nigeria \\ Email: dreciyidobi@yahoo.com, edeosita@yahoo.com,dreciyidobi@yahoo.com,dreciyidobi@yahoo.com, \\ cunwadinigwe@yahoo.co.uk, ‘toezigbo@yahoo.com, obadas2003@yahoo.com
}

How to cite this paper: Iyidobi, E.C., Ede, O., Obi, C.C., Onwuekwe, V.O., Nwadinigwe, C.U., Iyidobi, T.O. and Obadaseraya, O.R. (2021) Does the Breast Size in Females Correlate with the Severity of Mechanical Low Back Pain? Journal of Biosciences and Medicines, 9, 116-121.

https://doi.org/10.4236/jbm.2021.94009

Received: February 26, 2021

Accepted: April 18, 2021

Published: April 21, 2021

Copyright $\odot 2021$ by author(s) and Scientific Research Publishing Inc. This work is licensed under the Creative Commons Attribution International License (CC BY 4.0).

http://creativecommons.org/licenses/by/4.0/

(c) (i) Open Access

\begin{abstract}
Background: Large breast is postulated to cause undue tension in the paraspinal muscles and may result in back pain. Improved pain score following mammaplasty supports this assertion. Such a question has not been evaluated in an indigenous black population. Objectives: To assess the correlation between the breast cup size and the severity of low back pain among women with mechanical low back pain. Method: This was a prospective cohort study. Eighty-four women with chronic backpain attending the Orthopaedic clinic participated excluding psychogenic back pain. The breast cup sizes were estimated from the difference between the bust and band sizes measured with an inelastic tape. The severity of pain was determined with the Oswestry disability index (ODI) data analysed with IBM SPSS version 26. Results: The mean age was 49.35 years. The predominant breast cup size was A, (88\%), while the largest cup size was $\mathrm{C}$. The mean duration of symptoms and ODI score was 3.33 months $(\mathrm{SD}=2.63)$, and $42.30(\mathrm{SD}=16.98)$ respectively. The breast cup size did not show a positive correlation with ODI score, $r=-0.021$, $p=0.846$. Conclusion: The severity of mechanical low back pain does not correlate with the breast cup size.
\end{abstract}

\section{Keywords}

Breast Cup Size, Back Pain

\section{Introduction}

Low back pain is a common symptom among patients that presents to the outpatient orthopaedic clinic. It is defined as pain emanating from any region of the back between the inferior costal margins and the inferior gluteal folds [1]. The 
majority of low back pain is nonspecific and relates to degenerative changes in the spine as the patient advances in age. Such pain is said to be mechanical. Specific back pain is caused by trauma, tumour, infections or inflammatory conditions.

Large breast is associated with many symptoms in the literature, including low back pain, neck pain, axillary fold intertrigo, shoulder pain and mastalgia [2] [3] [4] [5]. The mechanism underlying the aetiology of back pain among women with large breasts is unknown. Some authors proposed that the breasts' weight distorts the spine's sagittal alignment by pushing the centre of gravity superiorly and anteriorly [6]. Such shift makes the paraspinal muscles to work harder to maintain spinal alignment and hence put under sustained tension.

Prolonged tension in the muscles, including the trapezius, erector spinae and the rhomboids, can cause muscle fatigue with resultant pain. Research has also shown an increase in the incidence of degenerative disc disease among women with breast hypertrophy [7]. Evidence from reduction mammaplasty seems to favour an association between breast size and back pain [8] [9] [10]. However, other studies have failed to show any significant association between them [11] [12]. The current study seeks to evaluate the association between breast cup size and severity of back pain among women with mechanical low back pain attending the clinic.

\section{Methods}

This work was a prospective cohort study involving 84 women at the outpatient Orthopaedic clinic of National Orthopaedic Hospital Enugu. The hospital is a tertiary hospital that provides specialist care in Orthopaedics, trauma, burns, plastic and reconstructive surgery. It is located in the southeastern part of Nigeria and runs a regular spine clinic. The hospitals' ethics committee approved the study before data collection.

The inclusion criteria were adult females aged above 18 years who consent to the study after a detailed explanation of the study protocol. The participants gave written consent to partake in the research. The authors excluded patients with back pain due to trauma, tumour, infection, and rheumatoid arthritis after examining the subjects' investigations and clinical features, including the MRI images. Also excluded were low back pain of psychogenic origin, pregnant females and women with a gynaecologic cause of referred back pain.

In the presence of a female nurse chaperone, one of the researchers measured the bust circumference of the patient over the crest of the breast with an inelastic tape after removing the brassiere. The measurement was repeated thrice, and took the average to avoid parallax error. Similarly, the same researcher measured the under-bust circumference under the breast fold and took an average of three measurements. The estimated breast cup sizes were recorded as the difference between the two measurements.

The breast cup sizes were classified as follows: A $(<19 \mathrm{~cm}), B(20-21 \mathrm{~cm}), \mathrm{C}$ 
$(22-24 \mathrm{~cm})$ and D $(>24 \mathrm{~cm})$ [13]. The same researcher administered the ODI questionnaire to the participants and classified the participants as follows: minimal disability ( $0 \%-20 \%)$, moderate disability $(21 \%-140 \%)$, severe disability (41\% - 60\%), crippled (61\% - 80\%) and bed-bound or exaggerated (80\% - 100\%). [14] The authors ran a Pearsons' correlation analysis on ODI score using the breast cup size as the regressor. The analysis was 2 -tailed, and a p-value less than 0.05 was deemed significant.

\section{Results}

Eighty-four women participated in this study with a mean age of 49.35 years (SD $=12.80)$. The average breast cup size was $14.58 \mathrm{~cm}(\mathrm{SD}=3.67)$, which is size A. Breast cup size A was the most frequent in this work, accounting for $88 \%$ of the total sizes. The mean duration of back pain was 3.33 months $(\mathrm{SD}=2.63)$, with a mean ODI score of 42.30 ( $S D=16.98)$. Table 1 illustrates the patients' diagnosis after reviewing the patients' clinical and laboratory findings, including X-ray and MRI images. Table 2 and Table 3 show the classes of the breast cup sizes and the subjects' ODI scores.

A Pearsons' correlation analysis did not show a positive relationship between increasing breast cup size and increasing ODI scores, $\mathrm{r}=-0.021, \mathrm{p}=0.846$. The distribution of the ODI scores among the various classes of breast cup size is shown in Table 4.

Table 1. The diagnoses of the back pain in the participants.

\begin{tabular}{ccc}
\hline Diagnosis & $\boldsymbol{n}$ & $\%$ \\
\hline Nonspecific low back pain & 46 & 54.8 \\
Disc prolapse with central canal stenosis & 22 & 26.2 \\
Facet arthropathy with lateral recces stenosis & 10 & 11.9 \\
Spondylolisthesis & 6 & 7.1 \\
Total & 84 & 100.0 \\
\hline
\end{tabular}

Table 2. The distribution of the breast cup size among the participants.

\begin{tabular}{ccc}
\hline Breast cup size $(\mathrm{cm})$ & $\boldsymbol{n}$ & $\%$ \\
\hline$A$ & 74 & 88.1 \\
$B$ & 5 & 6.0 \\
$C$ & 5 & 6.0 \\
Total & 84 & 100.0 \\
\hline
\end{tabular}

Table 3. The distribution of the ODI classes among the participants.

\begin{tabular}{ccc}
\hline ODI severity & $\boldsymbol{n}$ & $\%$ \\
\hline Mild & 8 & 9.5 \\
Moderate & 34 & 40.5 \\
\hline
\end{tabular}


Continued

\begin{tabular}{ccc}
\hline Severe & 27 & 32.1 \\
Crippling & 15 & 17.9 \\
Bed bound & 0 & 0.0 \\
Total & 84 & 100.0 \\
\hline
\end{tabular}

Table 4. The distribution of the pain severity by ODI classification among the various categories of breast cup sizes.

\begin{tabular}{ccccc}
\hline & Breast cup size A & Breast cup size B & Breast cup size C & Total \\
\hline Mild pain & $7(87.5 \%)$ & $1(12.5 \%)$ & $0(0.0 \%)$ & $8(100.0 \%)$ \\
Moderate pain & $31(91.2 \%)$ & $0(0.0 \%)$ & $3(8.8 \%)$ & $34(100.0 \%)$ \\
Severe pain & $23(85.2 \%)$ & $2(7.4 \%)$ & $2(7.4 \%)$ & $27(100.0 \%)$ \\
Crippling pain & $13(86.7 \%)$ & $2(13.9 \%)$ & $0(0.0 \%)$ & $15(100.0 \%)$ \\
\hline
\end{tabular}

\section{Discussions}

This study looked at the association between breast cup size and severity of low back pain in women coming to the Orthopaedic outpatient clinic with complaints of low back discomfort. The predominant breast cup size in this work was size A which is the smallest size. Women with large breasts tended to shy away from this study because of large breasted ladies' societal stigmatisation. This reason might explain the low prevalence of larger breasts rather than nonexistence.

The authors did not find a significant association between increasing breast cup size and severity of low back pain as measured by the ODI scale, at least between cup size A and C. This finding re-echoed the observations made by two different authors. Karaaslan et al. [11] studied the change in sagittal spine alignment after a reduction mammaplasty in women with breast hypertrophy. They found no significant change in thoracic kyphosis and lumbar lordosis of the spine after surgery. A similar observation was made by Lapid et al. [12], who showed no statistically significant improvement in back inclination angle after reduction mammaplasty.

These findings are significant since many authors have theorised that the change in spinal alignment caused by a large breast's heavyweight is responsible for causing back pain. Berberoglu et al. [8] found an improvement in all spinal angles and decreased backpain among women after reduction mammaplasty. Similarly, Foreman et al. [10] documented that large breast results in additional compressive forces on the spine and accelerates disc degeneration. They noted a $35 \%$ decrease in the compressive force on the spine after a reduction mammaplasty.

One study looked at back muscle activation via electromyography in women with different breast sizes. Alison Schinkel-Ivya and colleague [15] studied trunk muscle activation in 15 young women with no back pain. They looked at the as- 
sociation between increasing breast sizes and the degree of trunk muscle activation during upright and forward bending postures. They observed that as breast size increases, the muscle activation gets correspondingly higher. They concluded that breast size might result in an abnormal change in the physiology of trunk muscle.

It is vital to reiterate that studies that documented the relationship between back pain and breast size recruited women with breast hypertrophy who underwent mammaplasty. These patients already have complaints related to their breast size before seeing the surgeon and represent a subset of the total female population. Hence, it may not be accurate to generalise these studies' findings to the general population. However, this type of study is also difficult because of the research questions' sensitive nature.

Women are sensitive about their breast size, and many did not consent to this study, especially those with obviously large breast size. So, the study sample was skewed towards small breast sized participants. However, the non-significant association remained after weighting by the breast class frequency, showing that this effect might be real. Therefore, the authors concluded from this study that the breast cup size within the breast class of $A$ to $C$ does not correlate with the severity of low back pain. We recommend further studies on women with larger breast cup sizes than those seen in this work.

\section{Acknowledgements}

We wish to thank all those who in one way or the other contributed to the eventual successful completion of this manuscript, especially our valued patients who graciously gave consent for this study.

\section{Conflicts of Interest}

The authors declare no conflicts of interest regarding the publication of this paper.

\section{References}

[1] Chou, R. (2011) Low Back Pain (Chronic). AFP, 84, 437-438.

[2] Papanastasiou, C., Ouellet, J.A. and Lessard, L. (2019) The Effects of Breast Reduction on Back Pain and Spine Measurements: A Systematic Review. Plastic and Reconstructive Surgery-Global Open, 7, e2324. https://www.ncbi.nlm.nih.gov/pmc/articles/PMC6756677/ https://doi.org/10.1097/GOX.0000000000002324

[3] Krapohl, B.D. (2005) Functional Evaluation of the Spine in Patients with Breast Hypertrophy. Plastic Surgical Nursing, 25, 187-189.

https://doi.org/10.1097/00006527-200510000-00007

[4] Collins, E.D., Kerrigan, C.L., Kim, M., et al. (2002) The Effectiveness of Surgical and Nonsurgical Interventions in Relieving the Symptoms of Macromastia. Plastic and Reconstructive Surgery, 109, 1556-1566. https://doi.org/10.1097/00006534-200204150-00011 
[5] Chiu, T.W. and Stone, C. (2011) Stone's Plastic Surgery Facts and Figures. 3rd Edition, Cambridge University Press, Cambridge.

[6] Cano, S.J., Klassen, A.F., Scott, A.M., et al. (2012) The BREAST-Q: Further Validation in Independent Clinical Samples. Plastic and Reconstructive Surgery, 129, 293-302. https://doi.org/10.1097/PRS.0b013e31823aec6b

[7] Benditte-Klepetko, H., Leisser, V., Paternostro-Sluga, T., et al. (2007) Hypertrophy of the Breast: A Problem of Beauty or Health? Journal of Women's Health (Larchmt), 16, 1062-1069. https://doi.org/10.1089/jwh.2006.0183

[8] Berberoğlu, Ö., Temel, M. and Türkmen, A. (2015) Effects of Reduction Mammaplasty Operations on the Spinal Column: Clinical and Radiological Response. Aesthetic Plastic Surgery, 39, 514-522. https://doi.org/10.1007/s00266-015-0516-6

[9] Karabekmez, F.E., Gokkaya, A., Isik, C., et al. (2014) Does Reduction Mammaplasty Revert Skeletal Disturbances in the Vertebral Column of Patients with Macromastia? A Preliminary Study. Aesthetic Plastic Surgery, 38, 104-112. https://doi.org/10.1007/s00266-013-0194-1

[10] Foreman, K.B., Dibble, L.E., Droge, J., et al. (2009) The Impact of Breast Reduction Surgery on Low-Back Compressive Forces and Function in Individuals with Macromastia. Plastic and Reconstructive Surgery, 124, 1393-1399. https://doi.org/10.1097/PRS.0b013e3181b988aa

[11] Karaaslan, O., Demirkiran, H.G., Silistreli, O., et al. (2013) The Effect of Reduction Mammaplasty on the Vertebral Column: A Radiologic Study. The Scientific World Journal, 2013, Article ID: 701391. https://doi.org/10.1155/2013/701391

[12] Lapid, O., de Groof, E.J., Corion, L.U., et al. (2013) The Effect of Breast Hypertrophy on Patient Posture. Archives of Plastic Surgery, 40, 559-563. https://doi.org/10.5999/aps.2013.40.5.559

[13] McGhee, D.E. and Steele, J.R. (2006) How Do Respiratory State and Measurement Method Affect Bra Size Calculations? British Journal of Sports Medicine, 40, 970-974. https://doi.org/10.1136/bjsm.2005.025171

[14] Couper, J., Davies, J.B., Fairbank, J.C. and Obrien, J.P. (1980) The Oswestry Low Back Pain Disability Questionnaire. Physiotherapy, 66, 271-273.

[15] Schinkel-Ivy, A. and Drake, J.D.M. (2016) Breast Size Impacts Spine Motion and Posturalmuscle Activation. Journal of Back and Musculoskeletal Rehabilitation, 29, 741-748. 